\title{
Beyond category sorting and pleasantness rating: Inducing relational and item-specific processing
}

\author{
MILTON H. HODGE \\ University of Georgia, Athens, Georgia \\ and \\ HAJIME OTANI \\ Central Michigan University, Mount Pleasant, Michigan
}

\begin{abstract}
In most studies of relational and item-specific processing, category sorting and pleasantness rating have been the main procedures used to induce these two types of processing. Because the two types of processing have been studied in a wide range of memory phenomena (Hunt \& McDaniel, 1993), it is strange that other tasks have not been proposed and tested. The present experiment demonstrates that equivalent results can be obtained with three relational processing tasks (category sorting, narrative construction, and relational imagery) and equivalent results with three itemspecific processing tasks (pleasantness ratings, familiarity ratings, and single imagery).
\end{abstract}

In a series of experiments in which Einstein and Hunt (1980) and Hunt and Einstein (1981) sought to apply the results of two broad approaches to the study of human memory, organization and levels of processing, retrieval of verbal items was maximal when subjects had employed both relational and item-specific processing while encoding the material. These researchers pointed out that relational processing helps create a retrieval path by emphasizing the commonalities or similarities among the items. Item-specific processing, however, permits subjects to distinguish or discriminate among the individual items during retrieval. Relational processing encourages the integration and organization of a set of items, a view championed by the organizational approach to memory (Puff, 1979; Tulving \& Donaldson, 1972). Item-specific processing, however, seeks to maximize differences among the items, a view embodied in the levels-of-processing approach to memory (Cermak \& Craik, 1979). Hunt and McDaniel (1993) note that the latter viewpoint embodies the distinctiveness concept. Hunt and Einstein acknowledged that either type of processing will produce satis. factory retrieval, but that use of both types during the encoding of a set of items resulted in the greatest amount of retrieval, whether in recall or in recognition.

Subsequent research by these and other investigators (e.g., Einstein, McDaniel, Bowers, \& Stevens, 1984; Einstein, McDaniel, Owen, \& Cote, 1990; Hunt, Ausley, \&

We are indebted to Bruce Jacobs, Indira Balkissoon, and Tim Jones for their help with data collection and analysis, and to Richard C. Marsh for helpful comments about the manuscript. Correspondence concerning this article should be addressed to M. H. Hodge, 4074 Berkeley Mill Close, Duluth, GA 30136-5676 (e-mail: mhodge@) uga.cc.uga.edu).
Schultz, 1986; Hunt \& Seta, 1984; McDaniel, Einstein, $\&$ Lollis, 1988) has amply confirmed the preceding results under a variety of conditions. Furthermore, the distinction between relational and item-specific processing has also been invoked to explain many well-established memory phenomena (Hunt \& McDaniel, 1993, offer a detailed summary). These include the generation effect (see, e.g., Gardiner \& Hampton, 1988; McDaniel \& Waddill, 1990; McDaniel, Waddill, \& Einstein, 1988), hypermnesia (Burns, 1993; Klein, Loftus, Kihlstrom, \& Aseron, 1989; Otani \& Hodge, 1991a), proactive interference (e.g., Burns, 1989), prose recall (e.g., Einstein et al., 1984; Einstein et al., 1990), self-referent encoding (e.g., Klein \& Loftus, 1988), the word frequency effect (Otani \& Whiteman, 1993), the concreteness effect (Marschark, 1985; Marschark \& Hunt, 1989), the blocking effect (Sharps \& Tindall, 1992), and the encoding difficulty effect (e.g., McDaniel, Einstein, Dunay, \& Cobb, 1986; McDaniel et al., 1988).

Despite this impressive range of phenomena, virtually all this research is based on a very limited methodological interpretation of the two types of processing. That is, relational processing has typically been induced by the category-sorting task adopted by Einstein and Hunt (1980) and Hunt and Einstein (1981), and item-specific process ing, by means of pleasantness ratings. In our own investigations (Otani \& Hodge, 1991a, 1991b; Otani \& Stimson, 1994; Otani \& Whiteman, 1993, 1994), we faithfully followed Hunt and Einstein's procedures. In the case of relational processing, our subjects sorted a list of words into six taxonomic categories by placing word cards face down in one of six spatial locations on a posterboard. Itemspecific processing was induced by telling subjects to rate the pleasantness of each word on a 5-point scale. Not 
surprisingly, these operations nearly always duplicated the results of Einstein and Hunt.

In time, we found that placing cards on a posterboard was not always practical or feasible, and we became interested in establishing other means of inducing relational and item-specific processing. An examination of the organizational and levels of processing literature (Cermak \& Craik, 1979) indicated that a number of other procedures would also probably achieve the same effects as do category sorting and pleasantness rating.

In the present investigation, we sought specifically to compare the effects of three relational and three itemspecific procedures under the same experimental conditions. We chose the six procedures from prior research that claimed or seemed to claim that the procedures induced relational or item-specific processing. The three relational procedures and their source were category sorting (Einstein \& Hunt, 1980; Hunt \& Einstein, 1981), narrative construction (Bower \& Clark, 1969), and relational imagery (Begg, 1978; Bower, 1970; McGee, 1980; Schwartz \& Humphreys, 1974). The item-specific procedures and their source were pleasantness rating (Einstein \& Hunt, 1980; Hunt \& Einstein, 1981; Packman \& Battig, 1978; Toglia \& Battig, 1978), familiarity rating (Packman \& Battig, 1978; Toglia \& Battig, 1978), and single imagery (Begg, 1978; Bower, 1970; McGee, 1980). Still other tasks appear to induce relational and itemspecific processing (Cermak \& Craik, 1979), but we chose procedures that we think are especially straightforward, easy to implement, and reliable. Our main goal was to increase, if possible, the number of relational and itemspecific procedures that yield the same result, given the same input items and the same experimental conditions.

Because the effectiveness of the two types of processing is also a function of list structure (Einstein \& Hunt, 1980; Hunt \& Einstein, 1981), we examined the three versions of each type of processing with words drawn from taxonomic categories (the related list) and with words drawn from fuzzy categories (the unrelated list) that we constructed for the experiment. Einstein and Hunt (1980) and Hunt and Einstein (1981) have shown that itemspecific processing is more effective with words from taxonomic categories than from fuzzy categories, and that relational processing is more effective with words from fuzzy categories than from taxonomic categories. Words from taxonomic categories already possess a good deal of relational information and hence should benefit from processing that makes the words more distinctive during retrieval. In contrast, words from fuzzy categories are relatively distinct and thus should benefit from relational processing.

\section{METHOD}

With certain exceptions, the experiment generally followed Experiments 1 and 2 in Einstein and Hunt (1980).

\footnotetext{
Design and Subjects

The two list types (related and unrelated) and the six processing strategies (three relational and three item-specific) were orthogo-
}

nally combined to create $2 \times 6$ or 12 treatment conditions, each administered to an independent group of 28 subjects. In each group, subjects were presented a word list in one of two orders and were given a recognition test in one of two orders (see below). Thus, when the two presentation orders and the two test orders were combined with the treatment variables, the design was a $2 \times 6 \times 2 \times$ 2 complete factorial, with 7 subjects assigned randomly to each of the 48 treatment conditions, a total of 336 subjects.

The subjects participated to fulfill a course requirement in introductory psychology and were run in groups of $1-6$.

\section{Materials}

For the related word list, we simply used the items selected by Einstein and Hunt (1980), six items each from six categories in the Battig and Montague (1969) norms. The 36 words were arranged in the random order constructed by Einstein and Hunt and were then reversed to create a second list. As mentioned previously, half of the subjects in each experimental group received one of the orders and half received the other order. The recognition tests came directly from Einstein and Hunt (1980). They consisted of a randomized sequence of the 36 stimulus items plus 108 distractors, and the reverse sequence.

To construct the unrelated word list, we followed the general procedure of Einstein and Hunt (1980) in their Experiment 2. We asked graduate students to nominate concrete nouns that they thought were representative of 10 broad categories: things that were SOFT, ROUND, BIG, COLD, Or LOUD; things found in WATER, OFFICES, or MUSEUMS; or things that could SMELL or BURN. We then chose a set of 18 words each from 6 of the categories for use in the stimulus list of 36 or as distractors in the recognition test. Nine words were also chosen from the 4 remaining categories for additional distractors in the recognition test. The stimulus list and the recognition test were randomized and reversed in the same manner as were the taxonomic words.

The stimulus items were printed individually on $3 \times 5$ in. cards while the recognition items were printed on legal-sized paper. Instructions and experimental directions were duplicated and assembled in booklets to be read aloud by the experimenter and silently by each subject. A page of two-digit random numbers for use in a distractor task, a blank page for free recall, a recognition test, a postexperimental questionnaire, and a debriefing statement were included in the booklets.

\section{Procedure}

The experimenter began each session by reading a set of instructions aloud while subjects silently read a written version. When the experimenter had answered any questions and consent forms had been signed, the subjects were instructed to turn over the 1 st card in the deck of 36 , read the word silently while the experimenter pronounced it aloud, and then perform the processing strategy appropriate to the experimental condition. The sorting task required the subjects to place each card face down under the appropriate category label pasted on the posterboard. Subjects who rated the pleasantness or familiarity of the words wrote numerical responses $(1-5)$ on a prepared rating scale. The narrative construction group was instructed to create a story for each successive group of four words. The relational imagery subjects were told to create a mental image that included the objects in each successive group of four words. And finally, subjects in the single imagery condition were asked to form a mental image of the object denoted by each word. Subjects in all groups processed the remaining cards in the same manner at a presentation rate set by the slowest subject in the session. (Graf and Mandler, 1984, have shown that group pacing is an effective presentation tool.)

When all subjects had finished with the deck of cards, they performed a distractor task (digit cancellation) for $2 \mathrm{~min}$ that was administered to minimize any recency effects. Next, subjects were instructed to recall and write in any order as many words as possible 
in the deck of cards. The experimenter stopped the task 1 min after the last written response of any subject. All subjects were then given a recognition sheet of 144 words and asked to circle any word that they thought was in the deck of cards. The subjects also rated their confidence in their recognition responses on a 3-point scale. Again, the experimenter stopped the task $1 \mathrm{~min}$ after the last written response.

Finally, the subjects completed a brief questionnaire about the experiment and then received a short debriefing. All experimental sessions were completed within $60 \mathrm{~min}$.

\section{RESULTS AND DISCUSSION}

Three kinds of analyses, paralleling those of Einstein and Hunt (1980) and Hunt and Einstein (1981), were performed on the recall and recognition performance of the 12 groups. Each analysis began with an analysis of variance (ANOVA) and was followed, when appropriate, with Tukey multiple comparisons tests. In all analyses, $\alpha=.05$.

\section{Correct Recall}

Table 1 presents the mean number of words correctly recalled (maximum 36 ) and standard errors as a function of list type (related and unrelated) and the six processing strategies. Category sorting (SC), narrative construction (NC), and relational imagery (RI) required relational processing while pleasantness rating $(\mathrm{RP})$, familiarity rating (RF), and single imagery (SI) demanded item-specific processing. The ANOVA showed that list type $[F(1,288)=$ $13.86]$, processing strategies $[F(5,288)=4.36]$, and their interaction $[F(5,288)=4.61]$ were statistically significant $\left(M S_{\mathrm{e}}=24.67\right.$ for each test). Overall, items from related lists were better recalled than those from unrelated lists (17.97 vs. 15.95); however, Tukey tests among the cell means showed that recall of related items was superior to that of unrelated items only when subjects used one of the item-specific strategies (RP, RF, SI). Yet, when list type is ignored, words processed with one of the relational strategies (SC, NC, RI) were recalled more often on the average than words that received item-specific processing (compare row means). More importantly, however, there were no differences among the three relational strategies or among the three item-specific strategies. In other words, the relational strategies were all equivalent in their effects and the item-specific procedures were all equivalent in their effects. And furthermore, Tukey tests showed the same outcomes for comparisons limited to groups that received related lists and groups that received unrelated lists (comparisons among cell means of Table 1).

In their initial experiment, Einstein and Hunt (1980) asked some subjects to use a relational strategy with each word, some an item-specific strategy, and still others both types of strategy. Their results showed that recall and recognition were best when the words had received both types of processing. In their second experiment, relational strategies were more effective than item-specific procedures when the words came from unrelated lists, and vice versa with words from related lists. Einstein and Hunt reasoned that related words already possess some of the retrieval cues produced by relational processing, and thus benefit more from item-specific strategies. Unrelated words, by contrast, benefit more from relational processing. In the present data, Tukey tests of the related and unrelated groups that used the same strategy showed that recall of related words was significantly better than that of unrelated words only with the RF and SI strategies. Other comparisons of related and unrelated groups were in the direction predicted by Einstein and Hunt, but not statistically significant. In particular, unrelated groups were not statistically superior to related groups when they used relational strategies (SC, NC, RI).

However, the data also indicated that, with unrelated word lists, creating relational images (RI) for sets of four words led to greater recall (19.43) than did rating the familiarity (FR) of the words (12.07) or creating a single image (SI) for each word (13.5). Furthermore, sorting the words (SC) into taxonomic categories (17.71) and constructing narrative stories (NC) for sets of four words (17.46) produced more recall than did rating word familiarity (12.07). Other comparisons with the unrelated lists were not significant, nor were any of the comparisons among groups that received related words. Overall, however, we judge that these results support Hunt and Einstein's assertion that the effectiveness of relational and item-specific processing depends on the inherent relatedness among a list of items.

\section{ARC}

Although the analysis of the free recall data clearly shows that relational processing and the use of related words facilitated retrieval of items organized in taxonomic categories (and hindered retrieval with item-specific procedures and unrelated words), measures of category clustering in free recall can be used to obtain independent verification of these conclusions. These measures provide an index of the extent to which words from particular categories are recalled together during the recall test. Again following Einstein and Hunt (1980), adjusted ratio of clustering (ARC) scores (Roenker, Thompson, \& Brown, 1971) were calculated for the related (six taxonomic categories) and unrelated (six fuzzy categories)

Table 1

Mean Correct Free Recall and Standard Errors as a Function of List Type and Processing Strategy

\begin{tabular}{lrrrrrr}
\hline & \multicolumn{5}{c}{ List Type } \\
\cline { 2 - 3 } \multicolumn{1}{c}{ Processing Strategy } & \multicolumn{2}{c}{ Related } & & Unrelated & \\
\cline { 2 - 3 } \cline { 5 - 6 } Category sorting & 17.39 & .80 & 17.71 & .92 & 17.55 \\
Narrative construction & 17.79 & .94 & 17.46 & 1.09 & 17.62 \\
Relational imagery & 18.54 & 1.15 & 19.43 & 1.23 & 18.98 \\
Pleasantness rating & 17.86 & .58 & 15.54 & .88 & 16.70 \\
Familiarity rating & 18.32 & 1.00 & 12.07 & .80 & 15.20 \\
Single imagery & 17.93 & .92 & 13.50 & .66 & 15.71 \\
$M$ & 17.97 & & 15.95 & & \\
\hline
\end{tabular}


lists. Table 2 shows mean ARC scores and standard errors arranged in terms of list type and processing strategy. Higher ARC scores indicate greater category clustering.

An ANOVA indicated that the ARC scores varied reliably as a function of list type $[F(1,288)=93.86]$ and processing strategy $[F(5,288)=14.01]\left(\right.$ with $\left.M S_{\mathrm{e}}=.059\right)$. As expected, related lists produced larger ARC values than did unrelated lists, with category sorting of related words generating the largest score (.571) among the 12 conditions. Fairly large ARC values (row means in Table 2) were also observed with the three item-specific procedures, none of which differed from each other. With only 36 words to deal with, the six organizational categories were apparently pretty obvious even to the groups (RP, RF, SI) instructed to use an item-specific strategy.

The most interesting result is the low ARC scores obtained with the NC and RI strategies for both the related and unrelated lists. This outcome is exactly what would be expected if subjects were attempting to encode groups of four words and ignore the category information (taxonomic or fuzzy). Tukey tests showed that NC and RI differed significantly from the other processing strategies, but not from each other.

To test and extend the preceding conclusion, ARC scores were calculated again for each group, but this time with nine categories based on successive sets of four words. Thus, Category 1 included the first four words in a list, Category 2 the next four words, and so on to the last four words. In effect, the nine categories are the outcome that would be expected if subjects in the NC and RI groups met the requirements of these strategies. Mean ARC scores and standard errors as a function of list type and processing strategy are presented in Table 3. An ANOVA once again indicated significant differences between related and unrelated lists $[F(1,288)=43.12]$ and among processing strategies $[F(5,288)=44.51]\left(M S_{\mathrm{e}}=\right.$ .074). Inspection of Table 3 shows that ARC scores were highest in the NC and RI groups and lower in other groups-essentially the reverse of the ARC results with taxonomic and fuzzy categories (Table 2). Once again, Tukey tests demonstrated that the NC and RI groups differed from the other groups, but not from each other.

Table 2

Mean ARC Scores and Standard Errors as a Function of List Type and Processing Strategy

\begin{tabular}{|c|c|c|c|c|c|}
\hline \multirow[b]{3}{*}{ Processing Strategy } & \multicolumn{4}{|c|}{ List Type } & \multirow[b]{3}{*}{$M$} \\
\hline & \multicolumn{2}{|c|}{ Related } & \multicolumn{2}{|c|}{ Unrelated } & \\
\hline & $M$ & $S E$ & $M$ & $S E$ & \\
\hline Category sorting & .571 & .05 & .278 & .04 & .424 \\
\hline Narrative construction & .201 & .06 & .068 & .04 & .134 \\
\hline Relational imagery & .276 & .06 & -.013 & .03 & .131 \\
\hline Pleasantness rating & .425 & .04 & .220 & .04 & .322 \\
\hline Familiarity rating & .525 & .03 & .214 & .05 & .369 \\
\hline Single imagery & .426 & .06 & .116 & .04 & .270 \\
\hline$M$ & .404 & & .147 & & \\
\hline
\end{tabular}

Note-ARC scores are based on taxonomic (related) and fuzzy (unrelated) word categories.
Table 3

Mean ARC Scores and Standard Errors as a Function of List Type and Processing Strategy

\begin{tabular}{|c|c|c|c|c|c|}
\hline \multirow[b]{3}{*}{ Processing Strategy } & \multicolumn{4}{|c|}{ List Type } & \multirow[b]{3}{*}{$M$} \\
\hline & \multicolumn{2}{|c|}{ Related } & \multicolumn{2}{|c|}{ Unrelated } & \\
\hline & $M$ & $\overline{S E}$ & $M$ & $S E$ & \\
\hline Category sorting & -.095 & .03 & .021 & .04 & -.036 \\
\hline Narrative construction & -.346 & .06 & .666 & .05 & .506 \\
\hline Relational imagery & .341 & .06 & .619 & .07 & .480 \\
\hline Pleasantness rating & .006 & .02 & .146 & .06 & .076 \\
\hline Familiarity rating & -.059 & .03 & .141 & .08 & .041 \\
\hline Single imagery & -.032 & .03 & .090 & .07 & .028 \\
\hline$M$ & .084 & & .280 & & \\
\hline
\end{tabular}

Note - ARC scores are based on successive sets of four related or unrelated words.

An unexpected outcome of the ARC analyses is their apparent sensitivity to the efficacy of the various processing strategies. The ARC scores make it very clear that NC and RI are not effective processing strategies when word lists are organized by taxonomic or fuzzy categories. At the same time, when the ARC analysis was based on categories (successive sets of four words) compatible with the processing implications of the NC and RI procedures, the ARC scores clearly reflected the subjects' effective use of these strategies and their disregard of the taxonomic and fuzzy categories. So, at least with the present data, ARC analyses offer a useful analytical tool to assess the effectiveness of various processing strategies.

\section{Recognition}

Table 4 presents corrected recognition scores (hits minus false alarms) and standard errors organized by list type and processing strategy. In parallel with the correct recall data, an ANOVA indicated significant differences as a function of list type $[F(1,288)=14.06]$, processing strategy $[F(5,288)=10.00]$, and their interaction, $[F(5,288)=3.19]\left(M S_{\mathrm{e}}=25.49\right.$ for each test $)$. As expected, recognition was significantly better with unrelated than with related words. Tukey tests among the row means showed that RP and RF, item-specific procedures, produced more recognition than did $\mathrm{SC}, \mathrm{NC}$, or $\mathrm{RI}$, the three relational strategies. SI was better than NC, but not better than the SC and RI procedures. However, the most important result is that there were no differences among the relational strategies (SC, NC, RI) or among the itemspecific procedures (RP, RF, SI). This is the same as the conclusion obtained with the recall data.

Consistent with Einstein and Hunt's argument that item-specific processing is more effective with related than with unrelated words, Tukey tests indicated that both $\mathrm{RP}$ and RF led to better recognition than did SC, NC, and $\mathrm{RI}$ in the related, but not the unrelated, lists. At the same time, none of the relational strategies produced higher recognition than did the item-specific procedures with unrelated lists. 
Table 4

Mean Correct Recognition (Hits Minus False Alarms) and Standard Errors as a Function of List Type and Processing Strategy

\begin{tabular}{lrrrrrr}
\hline & \multicolumn{4}{c}{ List Type } \\
\cline { 2 - 3 } & \multicolumn{3}{c}{ Related } & \multicolumn{2}{c}{ Unrelated } & \\
\cline { 2 - 3 } \cline { 5 - 6 } Processing Strategy & $M$ & $S E$ & & $M$ & $S E$ & $M$ \\
\hline Category sorting & 23.75 & 1.08 & 29.75 & .92 & 26.75 \\
Narrative construction & 25.07 & 1.14 & 27.07 & 1.13 & 26.07 \\
Relational imagery & 25.57 & 1.18 & 28.36 & 1.12 & 26.96 \\
Pleasantness rating & 30.96 & .64 & 31.54 & .64 & 31.25 \\
Familiarity rating & 30.86 & .68 & 29.64 & .92 & 30.25 \\
Single imagery & 28.29 & .92 & 30.54 & .90 & 29.41 \\
$M$ & 27.42 & & 29.48 & & \\
\hline
\end{tabular}

\section{CONCLUSION}

Despite some inconsistencies among comparisons of the 12 processing groups with the four dependent variables, the general outcome of the experiment was consistent with Einstein and Hunt's (1980; Hunt \& Einstein, 1981) notions about the role of relational and itemspecific processing of related and unrelated word lists. More useful to researchers who employ these processing strategies is the availability of three relational strategies that produce similar results and three item-specific procedures that produce similar results. No longer are investigators limited to category sorting and pleasantness ratings, the old standbys in Hunt and Einstein's experiments and those of others (e.g., Otani \& Hodge, 1991a) who have made use of the relational and item-specific distinction. Nevertheless, further study is needed to determine whether the equivalent results of the relational tasks and those of the item-specific procedures share the same underlying processes. For example, narrative construction and relational imagery may not involve the same processes as does category sorting. Yet, it is remarkable that the three relational procedures generated statistically indistinguishable outcomes.

\section{REFERENCES}

Battig, W. F., \& Montague, W. E. (1969). Category norms for verbal items in 56 categories: A replication and extension of the Connecticut category norms. Journal of Experimental Psychology Monographs, 80(3, Pt. 2).

BEGG, I. (1978). Imagery and organization in memory: Instructional effects. Memory \& Cognition, 6, 174-183.

BowER, G. H. (1970). Imagery as a relational organizer in associative learning. Journal of Verbal Learning \& Verbal Behavior, 9, 529-533.

BOWER, G. H., \& ClARK, M. C. (1969). Narrative stories as mediators for serial learning. Psychonomic Science, 14, 181-182.

Burns, D. J. (1989). Proactive interference: An individual-item versus relational processing account. Journal of Memory \& Language, $\mathbf{2 8}$ 345-359.

BurNs, D. J. (1993). Item gains and losses during hypermnesic recall: Implications for the item-specific-relational information distinction. Journal of Experimental Psychology: Learning, Memory, \& Cognition, 19, 163-173.

Cermak, L. S., \& Craik, F. I. M. (Eds.) (1979). Levels of processing in human memory. Hillsdale, NJ: :.rlbaum.
Einstein, G. O., \& Hunt, R. R. (1980). Levels of processing and organization: Additive effects of individual-item and relational processing. Journal of Experimental Psychology: Human Learning \& Memory, 6, 588-598.

Einstein, G. O., McDaniel, M. A., Bowers, C. A., \& Stevens, D. T. (1984). Memory for prose: The influence of relational and propositionspecific processing. Journal of Experimental Psychology: Learning, Memory, \& Cognition, 10, 133-143.

Einstein, G. O., McDaniel, M. A., Owen, P. D., \& Cote, N. C. (1990). Encoding and recall of texts: The importance of material appropriate processing. Journal of Memory \& Language, 29, 566-581.

GardinER, J. M., \& HAMPTON, J. A. (1988). Item-specific processing and the generation effect: Support for a distinctiveness account. American Journal of Psychology, 101, 495-504.

GraF, P., \& MANDLER, G. (1984). Activation makes words more accessible, but not necessarily more retrievable. Journal of Verbal Learning \& Verbal Behavior, 23, 553-568.

Hunt, R. R., Ausley, J. A., \& Schultz, E. E., JR. (1986). Shared and item-specific information in memory for event descriptions. Memory \& Cognition, 14, 49-54.

Hunt, R. R., \& EInStein, G. O. (1981). Relational and item-specific information in memory. Journal of Verbal Learning \& Verbal Behavior, 20, 497-514.

Hunt, R. R., \& MCDANiEL, M. A. (1993). The enigma of organization and distinctiveness. Journal of Memory \& Language, 32, 421-445.

Hunt, R. R., \& SeTA, C. E. (1984). Category size effects in recall: The roles of relational and individual item information. Journal of Experimental Psychology: Learning, Memory, \& Cognition, 10, 454464.

KLEIN, S. B., \& LofTus, J. (1988). The nature of self-referent coding: The contributions of elaborative and organizational processes. Journal of Personality \& Social Psychology, 55, 5-11.

Klein, S. B., Loftus, J., Kinlstrom, J. F., \& Aseron, R. (1989). Effects of item-specific and relational information on hypermnesic recall. Journal of Experimental Psychology: Learning, Memory, \& Cognition, 15, 1192-1197.

MARSCHARK, M. (1985). Imagery and organization in the recall of prose. Journal of Memory \& Language, 24, 734-745.

Marschark, M., \& HUNT, R. R. (1989). A reexamination of the role of imagery in learning and memory. Journal of Experimental Psychology: Learning, Memory, \& Cognition, 15, 710-720

McDaniel, M. A., Einstein, G. O., Dunay, P. K., \& Cobb, R. E. (1986). Encoding difficulty and memory: Toward a unifying theory. Journal of Memory \& Language, 25, 645-656.

McDaniel, M. A., EINSTEIn, G. O., \& Lollis, T. (1988). Qualitative and quantitative considerations in encoding difficulty effects. Memory \& Cognition, 16, 8-14.

McDaniel, M. A., \& Waddill, P. J. (1990). Generation effects for context words: Implications for item-specific and multifactor theories. Journal of Memory \& Language, 29, 201-211.

McDaniel, M. A., Waddill, P. J., \& Einstein, G. O. (1988). A contextual account of the generation effect: A three-factor theory. Journal of Memory \& Language, 27, 521-536.

MCGEE, R. (1980). Imagery and recognition memory: The effects of relational organization. Memory \& Cognition, 8, 393-399.

OtAni, H., \& Hodge, M. H. (1991a). Does hypermnesia occur in recog. nition and cued recall? American Journal of Psychology, 104, 101 . 116.

Otani, H., \& Hodge, M. H. (1991b). Mechanisms of feeling of knowing: The role of elaboration and familiarity. Psychological Record, 41, 523-535

Otani, H., \& Stimson, M. J. (1994). A further attempt to demonstrate hypermnesia in recognition. Psychological Record, 44, 25-34.

Otani, H., \& Whiteman, H. L. (1993). Word frequency effect: A test of processing based explanation. Psychological Record, 43, 317-327.

Otani, H., \& Whiteman, H. L. (1994). Cued recall hypermnesia is not an artifact of response bias. American Journal of Psychology, 107, 401-421.

Packman, J. L., \& Battig, W. F. (1978). Effects of different kinds of semantic processing on memory for words. Memory \& Cognition, $\mathbf{6}$, $502-508$ 
PuFF, C. R. (Ed.) (1979). Memory organization and structure. New York: Academic Press.

Roenker, D. L., Thompson, C. P., \& Brown, S. C. (1971). Comparison of measures for the estimation of clustering in free recall. Psychological Bulletin, 76, 45-48

SCHWARTZ, R. M., \& HumphreYs, M. S. (1974). Recognition and recall as a function of instructional manipulations of organization. Journal of Experimental Psychology, 102, 517-519.

Sharps, M. J., \& Tindall, M. H. (1992). Relational and item-specific information in the determination of "blocking effects." Memory \& Cognition, 20, 183-191.

Toglia, M. P., \& BatTig, W. F. (1978). Handbook of semantic word norms. Hillsdale, NJ: Erlbaum.

Tulving, E., \& Donaldson, W. (Eds.) (1972). Organization of memory. New York: Academic Press.

(Manuscript received July 12, 1994;

revision accepted for publication November 30, 1994.) 